\title{
IMPACT OF INJECTION DISTRIBUTION ON CRYOGENIC ROCKET ENGINE STABILITY
}

\author{
J. Deeken, D. Suslov, S. Schlechtriem, and O. Haidn \\ German Aerospace Center (DLR) \\ Institute of Space Propulsion \\ Langer Grund, Hardthausen 74239, Germany
}

\begin{abstract}
The present publication addresses the actions taken to stabilize the combustion chamber assembly using a porous injector head described in a former publication and the test campaign during which the success of these measures was demonstrated. The first part deals with the nature of the reported combustion instability. A phenomenological explanation for its occurrence is presented and supported by experimental data. As a measure to counter this instability, two approaches were taken. First, a hydrogen cooled baffle segment, and second, a modification of the injection distribution of the injector head with respect to the presumed cause of the instability. While the baffle segment did not prove to be successful, the test runs with the modified injection pattern demonstrated the stable operation of the 80 -millimeter porous injector head over the whole range of operating conditions from 50 to 90 bar at hydrogen injection temperatures as low as $45 \mathrm{~K}$.
\end{abstract}

\section{INTRODUCTION}

To date, the concentric orifice, or coaxial injector element, is the most widely used injector element for liquid oxygen $(\mathrm{LOx}) / \mathrm{H}_{2}$ combustion. The combustion stability problems associated with this injection concept were reviewed by Hulka and Hutt [1]. During its early development phase (RL-10, J-2 in the U.S.), no combustion instabilities were encountered for this kind of injector element when operated at hydrogen injection temperatures exceeding $110 \mathrm{~K}$. However, at lower hydrogen injection temperatures, which might occur during the startup transient of the engine, the occurrence of combustion instability became a constant problem during the development of $\mathrm{LOx} / \mathrm{H}_{2}$ engines. The ratio of the injection velocities of hydrogen and oxygen was initially identified as a key parameter for the occurrence of combustion instability. Due to the increase in 
hydrogen density at lower temperatures, the hydrogen injection velocity is decreasing at constant mass flow rates and the velocity ratio decreases accordingly. All U.S. LOx $/ \mathrm{H}_{2}$ engines were operated at velocity ratios above 10 to ensure stable operation over a broad range of hydrogen temperatures. It was found that no combustion instability occurred for velocity ratios above 13. Research carried out at NASA Lewis Research Center indicated a dominant role of the hydrogen pressure drop for the stability boundaries of a coaxial injector element. A stability parameter correlating several parameters of injection including the hydrogen injection temperature was presented by Wanheinen et al. [2]. They introduced the critical hydrogen injection temperature as a way of rating the stability behavior of a $\mathrm{LOx} / \mathrm{H}_{2}$ engine. This temperature defines the boundary below which a rocket combustion chamber assembly exhibits an unstable mode of operation. A general tendency of coaxial injector elements to exhibit combustion instability at low mixture ratios and low velocity ratios was observed by several researchers [1]. Several methods exist to increase the stability margin of a coaxial injector. These include recessing the injector or increasing the mass flow rate per element at the expense of performance $[2,3]$. Sensitivity towards low velocity ratios and low mixture ratios was also shown to occur for plain orifice or showerhead injectors. This led to the conclusion that the mechanisms of instability are similar for this injector type.

An alternative injection concept for $\mathrm{LOx} / \mathrm{H}_{2}$ rocket engines is the concept of porous injection. Subscale combustion chambers featuring a porous injector head were tested for some years at the Institute of Space Propulsion of the German Aerospace Center (DLR) in Lampoldshausen. This concept has been investigated over a broad range of chamber pressures and mixture ratios at elevated hydrogen temperatures above $100 \mathrm{~K}$. It exhibits good combustion performance and stability nearly independent of changes in the propellant injection velocities [4].

A porous injector head consists of a large number of small diameter tubes for LOx injection and a porous face plate covering the space between individual LOx tubes. The whole hydrogen fuel is injected through the porous face plate. Porous face plates were used before (e.g., for the Space Shuttle Main Engine (SSME)), but in these cases, the fuel mass flow through the face plate was used for cooling purposes only, while the main fuel mass flow was injected through standard coaxial elements [1]. The use of a porous face plate was found to be beneficial for the stability behavior of a combustion chamber assembly [5]. In the case of a porous injector, the LOx injection reassembles a classic showerhead, while the hydrogen is injected homogeneously over the whole face plate area. Due to the drastic increase in hydrogen injection area, the injection velocity of the hydrogen is one to two orders of magnitude lower than in the case of coaxial injectors. Depending on injector head design and hydrogen injection temperature, the typical injection velocity ranges from 5 to $15 \mathrm{~m} / \mathrm{s}$. The injection velocity of the LOx is in the same range and the velocity ratio in the near 


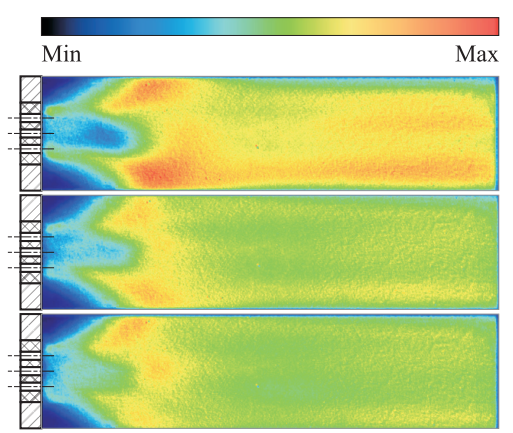

(a)

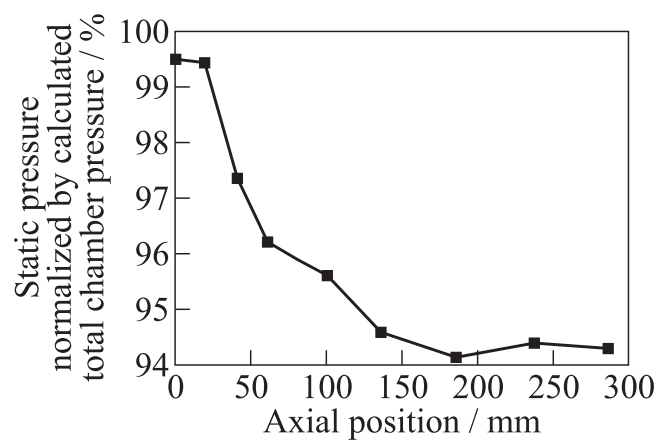

(b)

Figure 1 OH images of a porous injector with five injector elements [6] (a); and typical axial pressure distribution of a porous injector head with $68 \mathrm{LOx}$ injector elements [4] (b).

injector region is close to unity. Therefore, shear forces at the LOx injector tip are exceedingly small and play only a minor role in the atomization and mixing process. The initial mixing process close to the LOx posttips is believed to be dominated by diffusion processes instead, since the initial velocity difference between LOx jets and the surrounding hydrogen is close to zero. The large number of relatively small diameter jets results in a very large initial contact surface of oxygen and hydrogen compared to classical coaxial injector elements. The initial mixing by diffusion is further enhanced by this increase in contact surface area.

The main propellant atomization and mixing is believed to be controlled by shear forces resulting from the increasing velocity difference between the LOx jets or droplets and the accelerating combustion products. Former investigations indicated an onset of this main atomization and mixing zone at an axial distance from the face plate of approximately $30 \mathrm{~mm}$. Figure $1 a$ shows $\mathrm{OH}$ images obtained with a porous injector with five LOx injector elements at sub-, trans-, and supercritical conditions [6]. Four injector elements were arranged around a central injector element. These investigations used a 50-millimeter diameter subscale combustion chamber with an optical access. The length of the optical access was $100 \mathrm{~mm}$. The first $\mathrm{OH}$ intensity maximum is visible at a position approximately $25 \mathrm{~mm}$ downstream of the face plate. This intensity maximum is interpreted as a region of high reaction rates and heat release. This heat release is accompanied by fast acceleration of the main chamber flow and corresponding pressure drop in axial direction. Figure $1 b$ shows a typical axial pressure profile measured during a test campaign with a 50-millimeter diameter subscale combustion chamber and a 68-element porous injector [4]. This pressure profile 
exhibits a very steep slope starting at a similar axial position as the intensity maxima for the optically accessible combustion chamber shown in Fig. 1a. In this test run, the total loss in static pressure was about $5 \%$ of the calculated total chamber pressure. At $50 \mathrm{~mm}$ downstream of the face plate, the static pressure has already dropped by $2.5 \%$; so, about half of the pressure drop has already occurred over a relatively short distance. Both optical and pressure data, therefore, led to the conclusion that the region of the most intense reaction starts at approximately $30 \mathrm{~mm}$ downstream of the faceplate.

Several test runs with a 50-millimeter diameter subscale combustion chamber at a hydrogen injection temperature of about $50 \mathrm{~K}$ were successfully performed without signs of combustion instability. During a test campaign with a 80millimeter diameter subscale combustion chamber using a porous injector head, severe combustion instabilities were encountered at hydrogen injection temperatures around $45 \mathrm{~K}[7]$. The amplitude of the dynamic pressure during unstable operation exceeded $80 \%$ of the mean chamber pressure. The first tangential mode for this combustion chamber assembly at about $11.7 \mathrm{kHz}$ was the dominant mode of excitation. The injector head tested during this test campaign featured $168 \mathrm{LOx}$ injector tubes with a maximum inner diameter of $1.5 \mathrm{~mm}$. The porous face plate was made of sintered bronze with a porosity of $44 \%$.

The test campaign reported here aimed at eliminating the combustion instability encountered during the first test campaign and demonstrating a stable combustion over the whole range of the specified operating conditions. A basic understanding of the mechanism which triggered the observed combustion instability was necessary to come up with a working modification of the injector head configuration. An investigation of the dynamic pressure data gathered during the unsuccessful hot fire tests of the original API80-168 injector head was undertaken. During all test runs, spontaneous pressure peaks were encountered. The amplitude of these pressure perturbations sometimes exceeded $80 \%$ of the mean chamber pressure. Most of them decayed rapidly. Some of these pressure peaks led to high-frequency pressure oscillations, which triggered an automatic shutdown sequence, thus terminating the test run. These spontaneous pressure peaks appeared to be the prerequisite for the onset of combustion instability. The duration of such a pressure peak was found to be as long as $2 \mathrm{~ms}$, which is illustrated in Fig. 2. This duration is of the order of the residence time of a propellant volume in the combustion chamber. Such a strong pressure increase is likely to be caused by the reaction of a considerable amount of unburned propellants. The existence of such a large amount of unburned propellants either indicates a very poor overall propellant atomization and mixing or the extinction of the flame of one or more of the 168 injector elements. Former experiments with porous injectors using a 50-millimeter diameter subscale combustion chamber and $68 \mathrm{LOx}$ injector elements indicated good combustion efficiencies even for hydrogen injection temperatures as low as $50 \mathrm{~K}$ [4]. It was therefore concluded that the existence of large amounts of unburned propellants is not a result of 


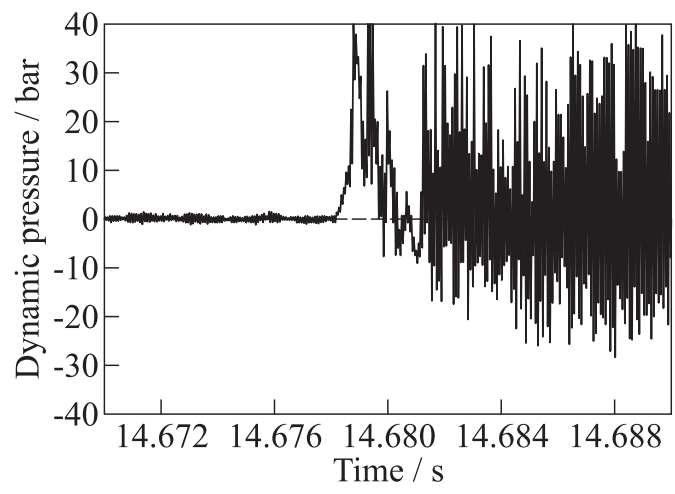

Figure 2 Dynamic pressure data at the onset of the combustion instability of one representative test run

poor atomization. More likely, it indicates flame extinction for one or more injector elements. After extinction of an injector element, unburned LOx and $\mathrm{H}_{2}$ accumulate and are reignited further downstream. The rapid combustion of the whole unburned propellant volume up to the injector face plate could lead to the observed spontaneous increase in chamber pressure.

The phenomenon of spontaneous pressure peaks was also reported from the F-1 engine development program. During the investigation of possible injector configuration, low-frequency high-amplitude pressure oscillations were triggered by spontaneous pressure peaks. These peaks appeared erratically. They were later attributed to rapid combustion of fuel pockets which were projected from the unstable cooling film into the combustion zone. This effect was believed to be self-sustaining, since the pressure peak would, in turn, disturb the injection conditions of the cooling film and, therefore, cause new fuel pockets to be projected into the combustion zone [8].

The location of the observed pressure peak is of great importance. The pressure antinode of the first tangential mode is located in the near-wall region of the combustion chamber. According to several publications summarized by Harrje and Reardon, a concentration of the energy release in this region increases the chances for triggering the first tangential mode, which was observed during the unstable test runs with the original porous injector head configuration [9].

The experiments with coaxial injectors and varying coverage of the face plate area were conducted by Wanheinen and Morgan [10]. During these investigations, the face plate area occupied by injector elements was varied by increasing the chamber diameter while the number and spacing of the injector elements as well as the nozzle throat area were kept constant. The most stable configuration 


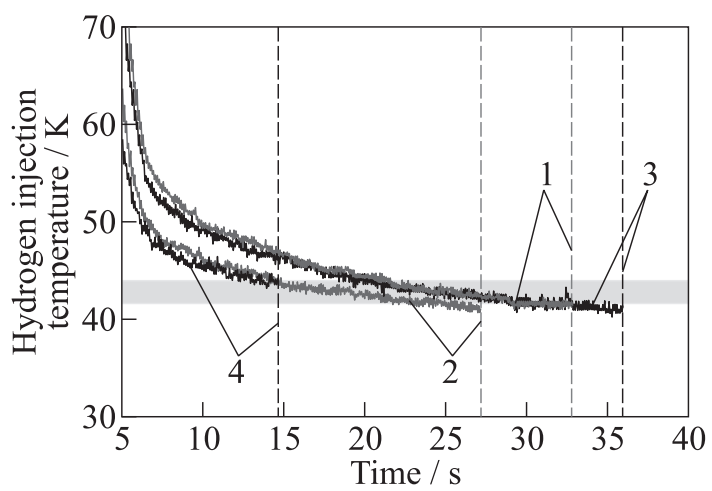

Figure 3 Hydrogen injection temperatures for four unstable test runs (original API80168 V1 configuration)

in terms of the critical hydrogen temperature was achieved with a full coverage of the face plate while a 70 percent face plate coverage yielded the highest critical hydrogen temperature.

Optical investigations of a porous injector by Lux et al. [6] indicated an attached and stable flame for hydrogen to oxygen velocity ratios of up to 2.11 at hydrogen injection temperatures of about $135 \mathrm{~K}$. The velocity ratio for the unstable test runs with the original API80-168 injector head ranged between 0.3 and 0.35 , due to the lower hydrogen injection velocities at lower injection temperature. The absolute value of the velocity difference was below $8 \mathrm{~m} / \mathrm{s}$. The resulting strain rates are of the order of $10^{4} \mathrm{~s}^{-1}$. Juniper et al. [11] numerically determined extinction strain rates for $\mathrm{LOx} / \mathrm{H}_{2}$ combustion. For hydrogen temperatures of $50 \mathrm{~K}$ and pressure of 1 bar, they calculated extinction strain rates of approximately $2 \cdot 10^{5} \mathrm{~s}^{-1}$. The strain rates necessary for extinction are believed to increase with increasing chamber pressure, thus further improving the resistance of the flame towards extinction by strain. The authors concluded that even for coaxial injectors operated with very low hydrogen injection temperatures, the extinction limits were not reached. In the case of porous injection, flame extinction due to strain is highly unlikely, since injection velocities are considerably lower.

The initial test runs with the API80-168 injector configuration exhibited an unstable behavior at hydrogen injection temperatures of about 41 to $44 \mathrm{~K}$. The evolution of the hydrogen inlet temperature is shown in Fig. 3. The grey area indicates the range of hydrogen injection temperatures at which the instabilities occurred. Since strain considerations were ruled out as a cause for the blowout of a single injector element, the hydrogen injection temperature remains as a cause for the postulated flame extinction. The original API80-168 configuration was 


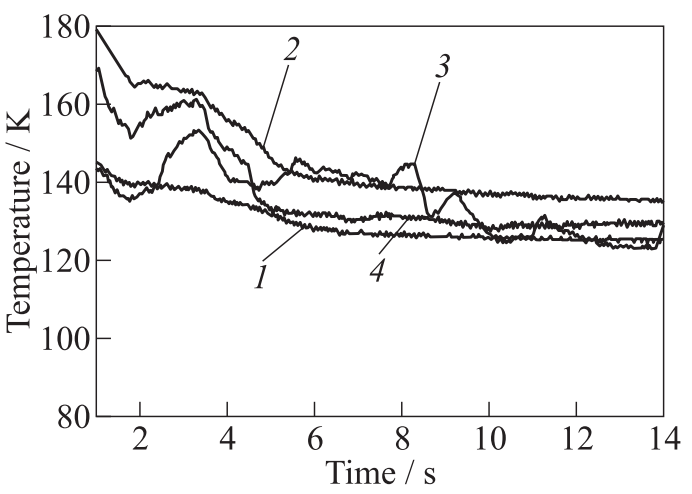

Figure 4 Gas temperatures $5 \mathrm{~mm}$ downstream of face plate during test run 4: 1 and 2 - between two injectors protruding 2 and $1 \mathrm{~mm}$, respectively; and 3 and $4-$ at injection position protruding 2 and $1 \mathrm{~mm}$, respectively

designed with a strong mixture ratio bias (oxidizer to fuel mixture ratio $\mathrm{ROF}<4$ vs. a mean ROF of 5.5). The near-wall region was supplied with a large surplus of hydrogen, which was achieved $(i)$ by reducing the outer row injector inner diameter from 1.5 to $1.2 \mathrm{~mm}$ and ( $i i)$ by increasing the injector-wall distance. Flame extinction in the outermost injector row was, therefore, promoted by two aspects:

(1) the heat release per element was reduced due to the decrease in jet surface area with decreasing jet diameter; and

(2) the large quantity of cold hydrogen injected in the near-wall region acted as a powerful heat sink.

The graph in Fig. 4 shows the temperature measurements at several positions $5 \mathrm{~mm}$ downstream of the porous face plate measured during test run 4 . The subscale combustion chamber used for the original API80-168 injector test was equipped with four thermocouples, which were extended into the combustion chamber at different angular positions. The minimum distance of a thermocouple to an LOx jet surface was $3.4 \mathrm{~mm}$. The measured gas temperatures remained below $150 \mathrm{~K}$ during steady-state operation. It was concluded that the heat release of a flame in the outermost injector row might not be sufficient to support the reaction below a certain hydrogen injection temperature. The most probable location of the observed pressure peaks is, therefore, the near-wall region of the combustion chamber. According to the findings presented by Harrje and Reardon [9], this promotes the triggering of the first tangential mode of instability. 


\section{STRATEGIES FOR INJECTOR HEAD MODIFICATION}

The encountered combustion instability can be countered by multiple measures. Passive measures aim at either increasing the energy losses of an established combustion instability, thus causing it to diminish (absorber cavities in the combustion chamber liner), or at changing the acoustic properties of the combustion chamber volume (quarterwave resonators and baffles).

A simple introduction of dampening elements like cavities was not considered sufficient due to the high-pressure amplitude of the encountered instabilities. Quarterwave resonators offer a possibility to counter a specific instability at a certain frequency. For the case presented here, the acoustic energy is concentrated in the first tangential mode at about $11.7 \mathrm{kHz}$. Therefore, the use of such quarterwave resonators would have been a promising way to suppress the encountered instability. The target frequency is dependent on the resonator dimensions and the speed of sound of the gas volume in the resonator [12]. To ensure a constant tuning, a constant speed of sound and, therefore, temperature of the gas volume inside the resonator cavity has to be maintained. This is usually accomplished by a constant temperature gas purge. Unfortunately, the implementation and run-in of such a resonator assembly would have exceeded the available test resources. Baffles, on the other hand, offer a good way to counter transversal modes of instability without high requirements regarding design and fine tuning. These baffles have to extend into the region of the most intense combustion in order to efficiently counter transversal modes. To ensure long test durations, the baffles have to be actively cooled, for example, by using a hydrogen dump cooling. Baffle segments introduce a distortion of the mixture ratio distribution across the chamber cross section. This stratification is likely to result in a degradation of performance due to incomplete combustion [12].

\subsection{Baffle}

The introduction of a three-bladed hydrogen dump cooled baffle section was chosen as a passive measure to counter the observed combustion instability of the API80-168 injector. This baffle assembly featured three nonsymmetrical radial baffles. It was introduced into the modular combustion chamber assembly as an individual segment directly downstream of the injector head. The segment was made of a copper alloy. To fit the baffle blades into the tightly spaced LOx injector pattern, a number of injectors had to be blocked. The length of the baffle blades was $50 \mathrm{~mm}\left(0.625 d_{\text {combustionchamber }}\right)$ at the combustion chamber wall and $15 \mathrm{~mm}\left(0.1875 d_{\text {combustion chamber }}\right)$ at the chamber axis. The central cut was introduced to allow for a short ignition delay between the individual 


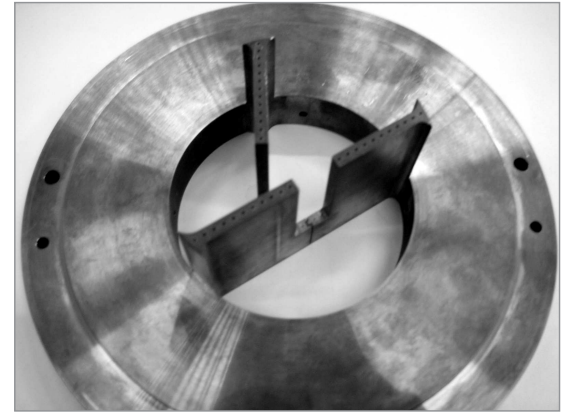

(a)

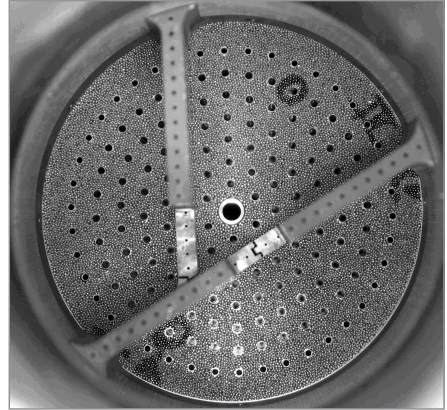

(b)

Figure 5 Three-bladed baffle segment (a); and API80-168 V1 injector head equipped with baffle segment $(b)$

baffle compartments, since only one compartment was directly covered by the pilot flame which was injected at the chamber axis. The baffle blades were expected to expand due to an increase in surface temperature. To avoid thermal stresses, the baffle blades were not connected, but separated by a small gap. This gap compensated for the expected thermal expansion but made them prone to deformation by pressure forces, which proved fatal during testing.

The baffle length of $50 \mathrm{~mm}$ was chosen to partially cover the region of the most intense propellant reaction and heat release. The baffle blades were cooled individually by a number of cooling channels which injected the cooling fluid at the baffle tip. The ratio of the cooling mass flow rate to the total fuel mass flow rate corresponded to the ratio of the fuel injection area blocked by the baffle to the total fuel injection area. In addition to this dump cooling efforts, the baffle blades were cooled by the main injector hydrogen flow, which was injected over the whole area of the face plate. The baffle segment is shown in Fig. 5.

\subsection{Injector Modification}

Apart from the purely passive measure of the baffle segment, the second approach was chosen. Since the triggering mechanism of the encountered combustion instability was identified, a change in injection distribution of the injector head was made to solve the problem. It seemed highly probable that the combustion instability was triggered by a pressure peak caused by the spontaneous reaction of a volume of unburned propellants, which accumulated due to the extinction of one or more injectors in the outer row of the injector pattern. Therefore, a new LOx injector pattern was designed, which aimed at lowering the probability of flame extinction close to the combustion chamber wall. 
In the case of porous injection, hydrogen is uniformly injected over the whole face plate area. The local propellant mixture ratio for a single injector element is, therefore, determined by the LOx injector element size, which determines the LOx mass flow rate, and the interinjector spacing, which determines the available hydrogen injection area and the corresponding fuel mass flow rate. The original LOx injector pattern aimed at lowering the hot gas temperature at the chamber wall by a strong mixture ratio trimming achieved by a large injector/wall distance and a decreased injector diameter in the outer row $\left(d_{\mathrm{LOx}}=1.2 \mathrm{vs} .1 .5 \mathrm{~mm}\right.$ for the rest of the injector pattern). The new injector pattern employed a single LOx injector diameter of $1.5 \mathrm{~mm}$ for all injectors and the injector/wall distance of the outer injector row was reduced. At the same time, the spacing between individual injectors was kept as uniform as possible and the whole injector pattern stretched to cover a greater fraction of the chamber cross section. The increase in injector diameter in the outer injector row increased the heat release per element for these injectors. The lower distance to the chamber wall reduced the amount of cold hydrogen in this region. These measures were believed to prevent the extinction of single injector elements and, therefore, to prevent the onset of combustion instability.

The injector head configuration using the new injector pattern was designated API80-168 V2, while the original injector head configuration is referred to as API80-168 V1. The LOx injector pattern and the mixture ratio distribution for both injector head configurations are illustrated in Fig. 6. The mixture ratio distributions for both configurations were determined by estimations based

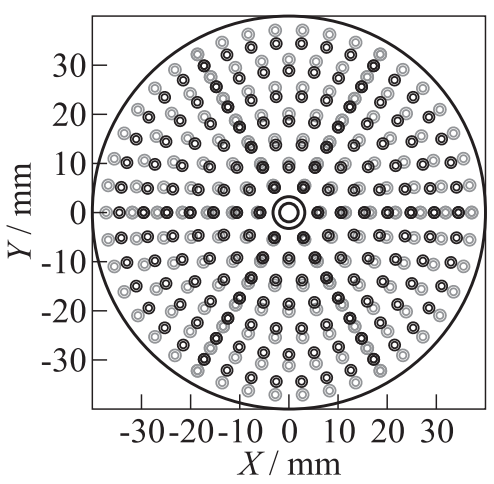

(a)

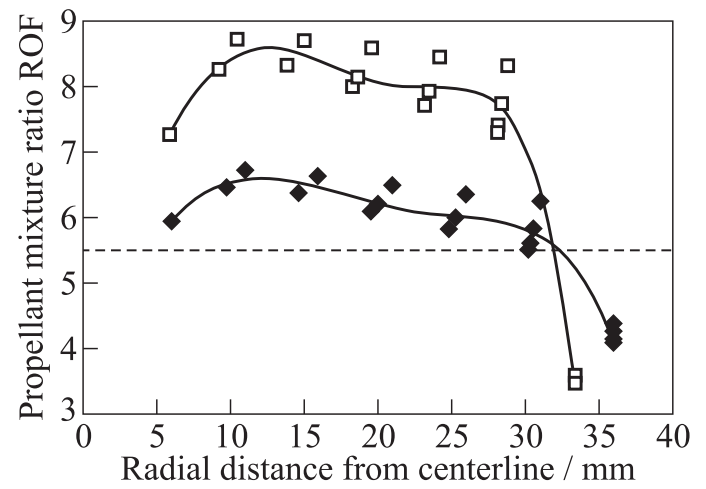

(b)

Figure 6 Changes in the LOx injector pattern from API80-168 V1 (black) to API80168 V2 (grey) (a); and estimated radial mixture ratio distribution for an injector head configuration with strong (API80-168 V1, open symbols) and with reduced (API80$168 \mathrm{~V} 2$, filled symbols) mixture ratio bias; dashed line refers to design $\mathrm{ROF}=5.5(b)$ 
on the distribution and size of the LOx injector tubes and were not measured directly during the experiment. The values presented in Fig. 6 are based on the assumption of uniform mass flow distribution across the LOx and $\mathrm{H}_{2}$ injection areas.

\section{EXPERIMENTAL SETUP}

\subsection{Subscale Combustion Chamber}

All tests were performed with a 80-millimeter diameter subscale combustion chamber with a total length of the cylindrical part of $318.5 \mathrm{~mm}$. The nozzle diameter was $50 \mathrm{~mm}$, resulting in a chamber contraction ratio of 2.56 . The total length from the injector face plate to the throat cross section was $367 \mathrm{~mm}$. This value was used for the determination of the frequencies of the longitudinal modes. The characteristic chamber length $L^{*}$ was $870 \mathrm{~mm}$ which is in the recommended range for $\mathrm{LOx} / \mathrm{LH}_{2}$ combustion [13]. The modular combustion chamber consisted of multiple cylindrical segments and a nozzle segment. The first segment downstream of the injector head was either a baffle segment (API80-168 V1 configuration) or a measurement ring (API80168 V2 configuration), each equipped with a number of pressure sensors. All following cylindrical segments and the nozzle segment featured an inner copper liner and were water cooled. The characteristic frequencies for this configuration are summarized in Table 1, assuming a mean speed of sound of about $1610 \mathrm{~m} / \mathrm{s}$ throughout the combustion chamber and the abovementioned characteristic dimensions. The speed of sound is estimated by a chemical equilibrium calculation [14]. Since the characteristic dimensions did not vary between the two configurations, no changes in the characteristic frequencies of the longitudinal modes were expected.

\subsection{Measurement Equipment}

The combustion chamber assembly was equipped with pressure and temperature sensors. Static pressure sensors were located at the propellant manifolds and at multiple positions along the combustion chamber wall. The sampling rate of these sensors was $100 \mathrm{~Hz}$. Since the evaluation of the combustion stability was the main goal of the test campaign presented here, the combustion chamber was 
Table 2 Positions of the dynamic pressure sensors

\begin{tabular}{lcrrrrrr}
\hline & Axial position, & \multicolumn{6}{c}{ Angular position of sensor } \\
\cline { 3 - 7 } & mm & \multicolumn{1}{c}{2} & 3 & 4 & 5 & 6 \\
\hline Plane 1 & 7.5 & $55^{\circ}$ & $145^{\circ}$ & $275^{\circ}$ & & & \\
Plane 2 & 68.5 & $9^{\circ}$ & $54^{\circ}$ & $90^{\circ}$ & $180^{\circ}$ & $270^{\circ}$ & $306^{\circ}$ \\
Plane 3 & 318.5 & $9^{\circ}$ & $54^{\circ}$ & $90^{\circ}$ & $180^{\circ}$ & $270^{\circ}$ & $306^{\circ}$ \\
\hline
\end{tabular}

equipped with a large number of dynamic pressure sensors arranged in three different planes. Table 2 summarizes the positions of the employed dynamic sensors. The calculation of the root mean square (rms) values was based on data acquired by the dynamic pressure sensors in plane 1 only. In addition to the combustion chamber itself, the fuel manifolds were monitored with dynamic pressure sensors. Kistler Modell 6053 sensors were used throughout the combustion chamber. The sampling rate was set to $100 \mathrm{kHz}$. Type $\mathrm{K}$ thermocouples were used for temperature measurements at various locations. Their sampling frequency was set to $100 \mathrm{~Hz}$.

\subsection{Operating Conditions}

The operating range for the API80-168 injector head configuration is illustrated in Fig. 7. This regime was divided into three different test sequences. Each test sequence covered a single pressure level with different propellant mixture ratio

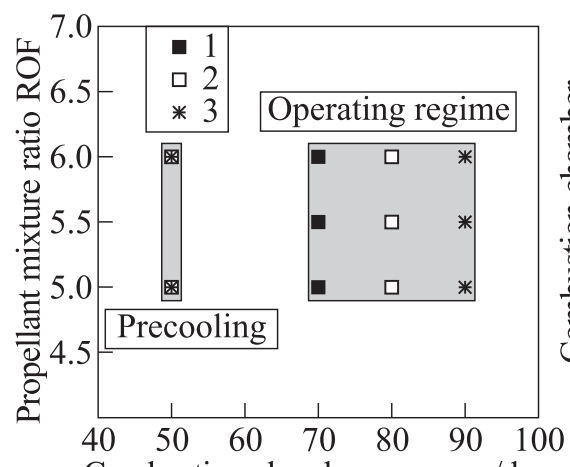

Combustion chamber pressure / bar

(a)

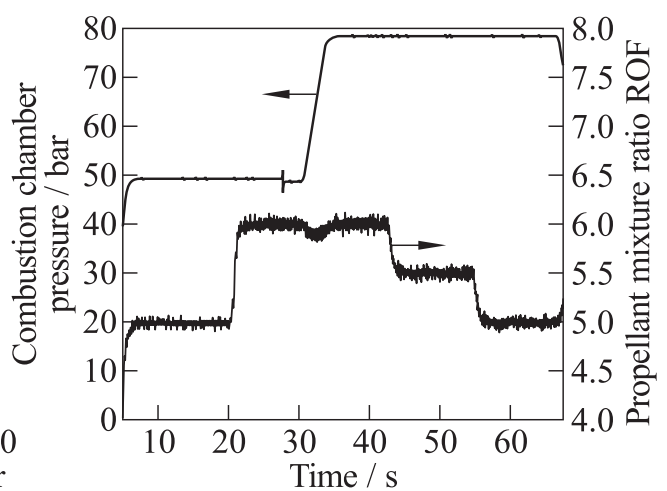

(b)

Figure 7 (Operating range for the API80-168 injector head (1-3 - sequences 13) (a); and typical pressure and ROF profiles (sequence 2) (b) 
settings. To assure a quasi-constant hydrogen injection temperature of about $45 \mathrm{~K}$, a precooling phase had to be introduced. During this precooling phase which was identical for all test sequences, the combustion chamber pressure was set to 50 bar. The combustion chamber assembly is not equipped with a nozzle extension during testing. Assuming a nozzle extension having an area ratio of 50 , these operating conditions would be equivalent to a thrust range of about 18 to $34 \mathrm{kN}$. Typically, the $\mathrm{P} 8$ test bench allows for a maximum of two test runs per test day when hydrogen at $45 \mathrm{~K}$ is required. The limited number of test days per test campaign resulted in the fact that only one test run per sequence could be performed.

\section{RESULTS}

All configurations tested and the corresponding results are summarized in Table 3 .

Table 3 Injector configurations, operating conditions and results

\begin{tabular}{|c|c|c|c|c|c|}
\hline \multirow{2}{*}{$\begin{array}{c}\text { Injector } \\
\text { configuration }\end{array}$} & \multirow[b]{2}{*}{ Baffle } & \multicolumn{2}{|c|}{ Operating conditions } & \multirow{2}{*}{$\begin{array}{l}\text { Combustion } \\
\text { efficiency }\end{array}$} & \multirow{2}{*}{$\begin{array}{l}\text { Stability } \\
\text { behavior }\end{array}$} \\
\hline & & $\begin{array}{c}\text { Pressure, } \\
\text { bar }\end{array}$ & $\mathrm{ROF}$ & & \\
\hline \multirow{2}{*}{ API80-168 V1 } & No & 50 & 5 & $88.9 \%-90.9 \%$ & $\begin{array}{l}\text { High frequency } \\
(1 \mathrm{~T}) \text { triggered by } \\
\text { pressure peaks }\end{array}$ \\
\hline & Yes & 50 & 5 & $89.0 \%$ & $\begin{array}{c}\text { No high frequency } \\
\text { pressure } \\
\text { peaks persist }\end{array}$ \\
\hline \multirow{4}{*}{ API80-168 V2 } & \multirow{4}{*}{ No } & 50 & $5-6$ & $97.6 \%-98.9 \%$ & stable \\
\hline & & 70 & $5-6$ & $98.2 \%$ & stable \\
\hline & & 80 & $5-6$ & $96.6 \%$ & stable \\
\hline & & 90 & $5-6$ & $99.3 \%$ & stable \\
\hline
\end{tabular}

\subsection{Test Runs with Baffle Segment}

The employed baffle segment failed during the very first test run. Pressure peaks similar to those observed with the original API80-168 V1 configuration were detected during the test run. A comparison of rms values calculated from dynamic pressure data acquired in Plane 1 (see Table 2) from test runs of the original configuration API80-168 V1 and the same configuration with baffle segment is shown in Fig. 8. The rms values were normalized to a static pressure measured at the same axial position. A 100-hertz high pass filter was applied to the dynamic 


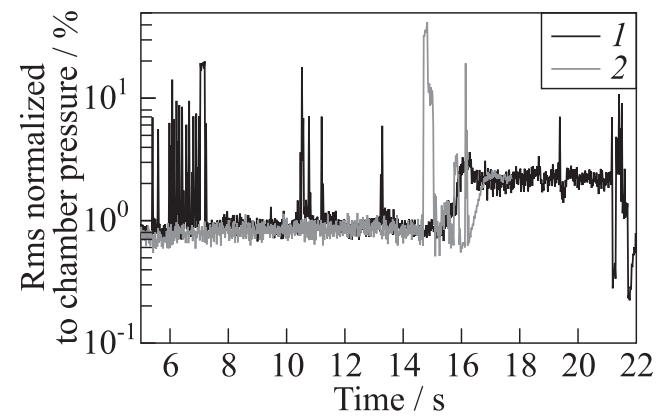

Figure 8 Calculated rms values of the dynamic pressure signal for the test run with baffle segment (1) and for a unstable test run of the original configuration without baffle $(2)$

pressure data before calculating the rms values to eliminate low-frequency pressure oscillation introduced by the propellant supply system at the test bench P8. The following rms calculation used a window size of 1000 dynamic pressure measurements. The rate at which the pressure peaks appeared was even higher compared to the configuration without baffle. However, no self-sustaining combustion instability was triggered by these pressure peaks. The test run was instead terminated due to the destruction of the baffle segment. An increase in rate of appearance of pressure peaks after implementation of a baffle to an existing injector pattern was reported from other engine development programs [12].

An inspection after the test run revealed that the baffle blades were bent by the mechanical forces resulting from pressure peaks exceeding \pm 20 bar inside individual compartments of the baffle. The blades were moved closer to active injector elements, which further reduced the mechanical strength of the material, since the cooling mass flow was not able to counter the increased heat load to the baffle blades. The permanent bending of baffle blades has also been observed during the F-1 and the Gemini engine programs, especially after bomb tests, which were conducted inside the baffle compartments [12]. This load case is very similar to the one resulting from the pressure peaks observed during this test run.

\subsection{Test Runs with Modified Injector Pattern}

The new injector head with the modified injector pattern exhibited stable combustion behavior over the specified range of operating conditions. Three test runs were performed to cover the operating range. The normalized rms values calculated from dynamic pressure sensors close to the injection plane are presented in Fig. 9. Although the rms at one occasion reached a value of about 


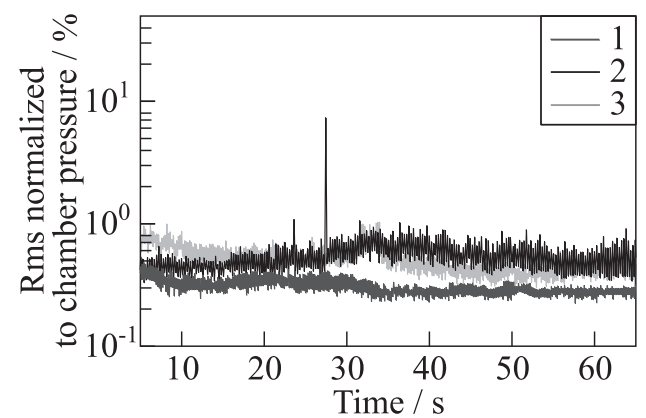

(a)

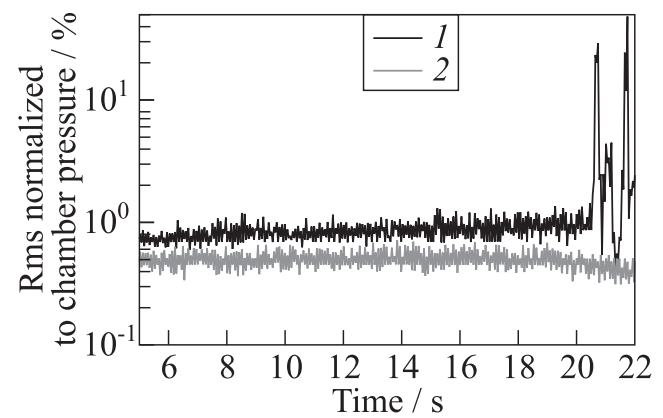

(b)

Figure 9 Normalized rms values for the API80-168 V2 configuration (1-3 - sequences 1-3) (a) and for the API80-168 V1 configuration without baffle (1) and the first test run of the API80-168 V2 (sequence 1) (2) configurations (b)

$8 \%$ of the chamber pressure during steady-state operation, no high frequency combustion instability was triggered. Except for some peaks, the rms values remained below $1 \%$ of the chamber pressure during steady-state operation. The normalized rms values for sequence 2 are slightly higher during the 80-bar phase of the test run than for the other sequences.

Figure $9 b$ shows a comparison of the rms values for test sequence 1 of the modified injector pattern API80-168 V2 and the original injector pattern V1 without baffle segment. The combustion roughness was considerably reduced by the modified injector pattern. The combustion efficiencies during steady-state operation are illustrated in Fig. 10. The characteristic velocity $c^{*}$, which is necessary for the determination of the combustion efficiency, was determined by combustion chamber pressure measurements at the end of the cylindrical chamber part. This measured characteristic velocity was compared to a theoretical value obtained by a chemical equilibrium calculation [14]. The calculated combustion efficiency was corrected with respect to the Mach number of the gas flow 


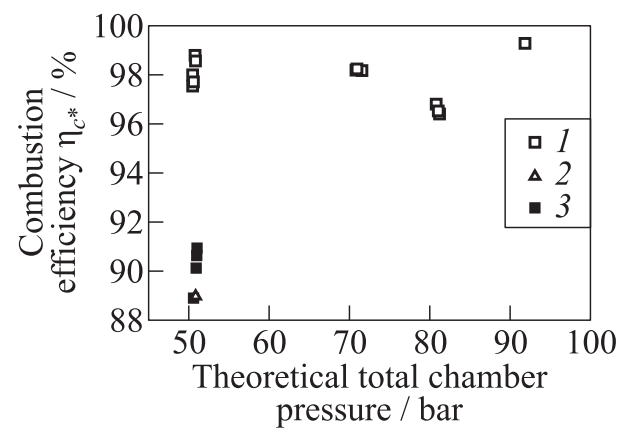

Figure 10 Combustion efficiency measured with modified injector pattern API80-168 V2, $L^{*}=870 \mathrm{~mm}(1)$ and with the original API80$168 \mathrm{~V} 1$ configuration with $\left(L^{*}=870 \mathrm{~mm}, 2\right)$ and without $\left(L^{*}=1126 \mathrm{~mm}, 3\right)$ baffle

inside the combustion chamber. Effects due to cooling and changes in throat area during the test run were not considered. The original unstable configuration API80-168 V1 (3) exhibited a very low combustion performance around $90 \%$, although the characteristic chamber length $L^{*}$ was much longer than the one during testing of the API80-168 V2 configuration. The central region of the original injector pattern was operated with a surplus of oxygen, due to the strong mixture ratio bias in the near-wall region. Apparently, the turbulence inside the combustion chamber was not strong enough to equalize this misdistribution. The test run with the original injector pattern and the additional baffle segment were performed with a decreased characteristic chamber length. This test run exhibited a slightly lower combustion efficiency (2) that can be explained by the lower characteristic chamber length and by the adverse effect of the mixture ratio misdistribution introduced by the baffle segment. The successful test runs with the new injector pattern API80-168 V2 (1) yielded combustion efficiencies ranging from $96.6 \%$ to $99.3 \%$. The operating points at 80-bar chamber pressure exhibit the lowest combustion efficiency. It has to be noted that the error margin of these values for the combustion efficiency is about $\pm 2 \%$ due to errors in pressure and mass flow rate measurements. Although the combustion chamber pressure was varied between 50 and 90 bar, which can be interpreted as a thrust variation by the same factor, no significant degradation of performance can be detected. This finding is similar to results obtained with a 50-millimeter diameter porous injector [4].

\section{CONCLUDING REMARKS}

Two measures to counter a combustion instability phenomenon observed during operation of a 80-millimeter diameter porous injector head with a $\mathrm{LOx} / \mathrm{H}_{2}$ propellant combination have been presented: $(i)$ an introduction of a dump cooled baffle segment; and (ii) a modification of the radial injection distribution. The baffle dimensions were designed with respect to the dominant mode of instability observed (the first tangential mode) and the axial heat release distribution 
typical for porous injectors. The second approach is aimed at eliminating the hypothetical cause of the observed instability. It was postulated that the instability was triggered by spontaneous pressure peaks which were, in turn, caused by the blowout of one or more injector elements and the following reignition of the unburned propellant volumes. Therefore, a modification of the original injector pattern towards more homogenous mixture ratio distribution was made.

The original injector head configuration was operated with hydrogen injection temperatures of about $45 \mathrm{~K}$ and both approaches were tested at identical operating conditions with respect to chamber pressure, mixture ratio, and injection temperatures. The application of the baffle segment to the original injector pattern did not prove to be successful in suppressing the pressure peaks. Although no combustion instability was triggered in this case, the baffle segment was lost due to excessive mechanical loads resulting from the pressure peaks. The modified injector pattern resulted in stable operation over the whole operating range (70-90 bar, ROF $=5-6$ ) with hydrogen injection temperatures around $45 \mathrm{~K}$. The measured combustion efficiencies range between $96.6 \%$ and $99.3 \%$. The change in injection distribution is believed to effectively prevent the blowout of injector elements. During operation at 80 bar, the rms of the dynamic pressure reached a value of $8 \%$ at one occasion. The combustion process immediately returned to normal operation. Special efforts to examine the stability margin of the injector assembly were not made. Standard procedures to determine the stability margin like bomb tests would probably lead to combustion instabilities in a similar way the pressure peaks observed for the original injector pattern did. The corresponding margins for dynamic stability are expected to be lower than for a combustion chamber equipped with standard coaxial elements. Therefore, the current design approach focuses on preventing pressure peaks as a necessary prerequisite for the onset of combustion instability.

\section{ACKNOWLEDGMENTS}

The authors would like to thank the P8 test bench crew for their contributions to the successful test campaign.

\section{REFERENCES}

1. Hulka, J., and J. Hutt. 1995. Instability phenomena in liquid oxygen/hydrogen propellant rocket engines. In: Liquid rocket engine combustion instability. Eds. V. Yang and W. E. Anderson. Progress in astronautics and aeronautics ser. Washington, DC: AIAA. 169:39-71. 
2. Wanheinen, J., C. Feiler, and C. Morgan. 1968. Effect of chamber pressure, flow per element, and contraction ratio on acoustic-mode instability in hydrogen-oxygen rockets. NASA TN D-4733.

3. Wanheinen, J., C. Feiler, and C. Morgan. 1966. Effect of propellant injection velocity on screech in 20000-pound hydrogen-oxygen rocket engine. NASA TN D-3733.

4. Deeken, J., D. Suslov, O. Haidn, and S. Schlechtriem. 2011. Combustion efficiency of a porous injector during throttling of a $\mathrm{LOx} / \mathrm{H}_{2}$ combustion chamber. In: Progress in propulsion physics. Eds. L. T. DeLuca, C. Bonnal, O. J. Haidn, and S. M. Frolov. EUCASS advances in aerospace sciences book ser. Moscow: TORUS PRESS. 2:251-64.

5. Wanheinen, J., N. Hannum, and L. Russell. 1967. Evaluation of screech suppression concepts in a 20,000-pound thrust hydrogen-oxygen rocket. NASA TM X-1435.

6. Lux, J., D. Suslov, and O. Haidn. 2008. On porous liquid propellant rocket engine injectors. Aerospace Sci. Technol. 12:469-77.

7. Deeken, J., D. Suslov, O. Haidn, and S. Schlechtriem. 2010. Design and testing of a porous injector head for transpiration cooled combustion chambers. 48th AIAA Aerospace Science Meeting. Orlando.

8. Oefelein, J., and V. Yang. 1993. Comprehensive review of liquid-propellant combustion instabilities in F-1 engines. J. Propul. Power 9:657-77.

9. Harrje, D., and F. Reardon. 1972. Liquid propellant rocket combustion instability. NASA SP-194.

10. Wanheinen, J., and C. Morgan. 1969. Effect of injection element radial distribution and chamber geometry on acoustic-mode instability in a hydrogen oxygen rocket. NASA TN D-5375.

11. Juniper, M., N. Darabiha, and S. Candel. 2003. The extinction limits of a hydrogen counterflow diffusion flame above liquid oxygen. Combust. Flame 135:87-96.

12. Keller, R. 1974. Liquid rocket engine combustion stabilization devices. NASA SP8113.

13. Huzel, D., and D. Huang. 1992. Modern engineering for design of liquid-propellant rocket engines. Progress in astronautics and aeronautics ser. Washington, DC: AIAA. 147.

14. Gordon, S., and B. McBride. 1994. Computer program for calculation of complex chemical equilibrium compositions and applications. Vol. 1: Analysis. NASA RP1311. 